\title{
Fluorescence in situ hybridization shows spatial distribution of as yet uncultured treponemes in biopsies from digital dermatitis lesions
}

\author{
Annette Moter, ${ }^{1}$ Gregor Leist, ${ }^{2}$ Roland Rudolph, ${ }^{2}$ Kirstin Schrank, ${ }^{3}$ \\ Bong-Kyu Choi, ${ }^{4}$ Michael Wagner ${ }^{5}$ and Ulf B. Göbel ${ }^{1}$
}

Author for correspondence: Ulf B. Göbel. Tel: +49302093 4715. Fax : +493020934703. e-mail: goebel@rz.charite.hu-berlin.de

\footnotetext{
1 Institut für Mikrobiologie und Hygiene,

Universitätsklinikum Charité, HumboldtUniversităt zu Berlin, Dorotheenstr. 96, D-10117 Berlin, Germany

2 Institut für VeterinärPathologie der Freien Universität Berlin, Straße 518, Nr. 15, D-14163 Berlin, Germany

3 Institut für Mikrobiologie und Tierseuchen der Freien Universität Berlin, Luisenstr. 56, D-10117 Berlin, Germany

4 Department of Oral Biology, Yonsei University, 134 Shinchon-Dong, 120-752 Seoul, Korea

5 Technische Universität München, Lehrstuhl für Mikrobiologie, Arcisstr. 16, D-80290 München, Germany
}

\begin{abstract}
Fluorescence in situ hybridization (FISH) was performed on sections of plasticembedded tissue using 165 rRNA-directed oligonucleotide probes to visualize uncultured treponemes in skin biopsies of cows with digital dermatitis. Plastic as embedding material allowed sectioning of hard and soft tissue with a defined thickness, avoiding the risk of dragging bacteria into the tissue while sectioning. Furthermore, it provided a good signal-to-noise ratio. Using this method the spatial distribution of three different bacterial phylotypes was visualized simultaneously within the tissue. Whereas debris covering the ulcers contained a mixture of different micro-organisms, a layering of certain treponemal phylotypes was observed deeper in the epidermis. Confocal laser scanning microscopy and subsequent three-dimensional reconstruction of series of optical sections confirmed that the treponemes migrated intercellularly around the cells, most of them directed towards the dermis. In situ hybridization on tissue embedded in plastic proved to be a useful method to study mixed bacterial infections since it combines excellent histological conservation of tissue with identification of bacterial species by simultaneous use of probes labelled with different fluorescent dyes. This technique may have implications for in situ detection, identification and localization of microorganisms in veterinary as well as in human medicine.
\end{abstract}

Keywords: treponemes, tissue sections, in situ hybridization, FISH

\section{INTRODUCTION}

In situ hybridization (ISH) has been proven to be a useful method for detection and identification of bacteria within their natural environments. It has been used to visualize uncultured micro-organisms to estimate their size, number and morphology (Amann et al., 1991; DeLong et al., 1989). Recently, it was applied to identify spirochaetes from digital dermatitis (DD) lesions in cattle (Choi et al., 1997). DD, first described by Cheli \& Mortellaro (1974), is an ulcerative epidermitis typically found at the plantar skin proximal to the heel bulbs of

Abbreviations: DD, digital dermatitis; CLSM, confocal laser scanning microscopy; FISH, fluorescence in situ hybridization; H\&E, haematoxylin/ eosin; $\mathrm{ISH}$, in situ hybridization. dairy cows and beef cattle. Clinically, it is characterized by wet, exudative and typically malodorous lesions with pain and swelling at the diseased site. DD causes substantial economic losses worldwide (Blowey \& Sharp, 1988; Weaver et al., 1993) due to lameness, reduced fertility and significant decrease in body weight and milk production.

Microscopic analysis of touch preparations of DD lesions typically shows spirochaetes as the predominant morphotype, suggesting a possible aetiological role for these organisms (Blowey et al., 1992; Done et al., 1993; Read et al., 1992). Recently, comparative $16 \mathrm{~S}$ rDNA analysis showed that these as yet unclassified DD spirochaetes are closely related to cultivable as well as to uncultured oral treponemes (Choi et al., 1997). Using $16 \mathrm{~S}$ rRNA-directed oligonucleotide probes in ISH of 
touch preparations, Treponema denticola-like spirochaetes were detected in the highest proportions among all treponemal species. However, it is not clear whether these organisms are simply commensals proliferating in the anaerobic milieu of a skin ulcer or actively involved in primary inflammation. Using Warthin-Starry (Blowey et al., 1994) or silver staining (Elias \& Bosma, 1987), DD spirochaetes have been detected within tissue sections. Light and transmission electron microscopy have indeed shown numerous spirochaetes between or inside necrotic cells within the stratum corneum and stratum granulosum, but again species identification was not possible by these methods.

The specific aim of this study was to identify treponemes directly within the epidermis and to visualize their spatial distribution using fluorescence in situ hybridization (FISH).

\section{METHODS}

Bacterial strains. The following bacterial strains were used as controls to optimize the ISH conditions: Treponema vincentii (ATCC 33580 and RITZ A), Treponema denticola (ATCC 33521), Treponema pectinovorum (ATCC 33768), Treponema socranskii subsp. buccale (ATCC 35534), Treponema socranskii subsp. socranskii (ATCC 35536), Treponema maltophilum (Wyss et al., 1996) and Treponema phagedenis subsp. reiteri (kindly provided by B. Wilske, Munich, Germany).

Processing of tissue specimens. Biopsies $(1 \times 1 \mathrm{~cm})$ were taken from typical DD lesions of 10 infected dairy cows from 10 different farms (Land Brandenburg, Germany) and transported to the laboratory immediately. All of the following steps were performed at a temperature of $4{ }^{\circ} \mathrm{C}$. The tissue was cut into slices with a maximum thickness of $0.3 \mathrm{~cm}$ and fixed with $3.7 \%(\mathrm{v} / \mathrm{v})$ formaldehyde in PBS ( $\mathrm{pH} \mathrm{7.4)}$ for at least $3 \mathrm{~h}$. The embedding procedure, utilizing cold polymerizing resin (Technovit 8100 , Kulzer), was performed according to the manufacturer's instructions. Briefly, the specimens were washed overnight in PBS containing $6.8 \%(\mathrm{w} / \mathrm{v})$ sucrose, dehydrated in acetone for $1 \mathrm{~h}$ and infiltrated with the plastic solution (Technovit 8100 base-liquid with hardener I) for at least $6 \mathrm{~h}$. After adding hardener II, the biopsies were aligned properly in the wells of histoform $S$ (Kulzer), sealed with cover foil and placed in the refrigerator. After polymerization, histoblocks were mounted on the specimen using Technovit 3040. The blocks were stored at $4{ }^{\circ} \mathrm{C}$ prior to sectioning. Formaldehyde-fixed biopsies were routinely embedded in paraffin in parallel. After dehydration in a graded alcohol series, they were transferred to paraffin via xylene and embedded in tissue-tec moulds (Kulzer).

Sectioning and light microscopy. Blocks were sectioned on a rotary microtome (Medim, Type DDM 0036) using steel knives with hard metal edges. Tissue sections $(4 \mu \mathrm{m})$ were straightened on sterile water, placed on silanized slides (Super Frost, Medim; 3-aminopropyltrimethoxysilane, Sigma) and stored at $4{ }^{\circ} \mathrm{C}$.

For histological evaluation, tissue sections were stained with haematoxylin/eosin (H\&E) and examined using an Axioskop microscope (Zeiss).

Oligonucleotide probes. Phylotype-specific oligonucleotide probe DDK4 (Table 1), corresponding to position 1246-1267 in Escherichia coli $16 \mathrm{~S}$ rRNA, was designed to be complementary to the sequence of a clone derived from a $16 \mathrm{~S}$ rDNA gene library of DD spirochaetes reported previously (Choi et al., 1997). Group-specific probes TRE I, II and IV (Table 1) were designed after comparative sequence analysis of clones from a $16 \mathrm{~S}$ rDNA library representing cultivable and as yet uncultured oral treponemes associated with periodontal disease (Choi et al., 1994; Moter et al., 1998). To assess specificity, probe sequences were compared with those of all $16 \mathrm{~S}$ rRNA entries in the EMBL and GenBank databases (July 1997) using the Husar program package (DKFZ, Heidelberg, Germany). In addition, all oligonucleotide probes were tested by dot-blot hybridizations against PCR-amplified $16 \mathrm{~S}$ rDNA from 34 bacteria. These controls included sequences from clones of a gene bank of uncultured oral treponemes derived from a $16 \mathrm{~S}$ rDNA library, cultivable Treponema species and oral pathogens as described previously (Moter et al., 1998; Choi et al., 1997). Cultivable representatives of these spirochaetal groups targeted by probes TRE I, II, IV and DDK 4 are $T$. vincentii, T. denticola, T. maltophilum and T. phagedenis, respectively (Table 1 ). EUB 338 ( $5^{\prime}$ GCTGCCTCCCGTAGGAGT), specific for the domain Bacteria, was used to visualize the entire bacterial population in the specimens (Amann et al., 1990). End-labelling (3') of oligonucleotide probes with Cy3dCTP or Cy5-dCTP [5-aminopropargyl-2'-deoxycytidine 5'triphosphate coupled to $\mathrm{Cy} 3$ (indocarbocyanine) or $\mathrm{Cy} 5$ fluorescent dye, Amersham] was performed enzymically using terminal transferase (Boehringer Mannheim). Fluoresceinlabelled $\left(5^{\prime}\right)$ probes were obtained from Tib Molbiol (Berlin).

FISH. Hybridization buffer contained $0.9 \mathrm{M} \mathrm{NaCl}, 20 \mathrm{mM}$ Tris $/ \mathrm{HCl}, \mathrm{pH} 7 \cdot 3$, and $0.01 \%$ SDS. The stringency was adjusted by varying the formamide concentration from 0 to $30 \%(\mathrm{v} / \mathrm{v})$ depending on the oligonucleotide probe used. To assess specificity of the probes, all available Treponema strains served as controls, using fixed cells (Moter et al., 1998) or

Table 1. Treponeme-specific oligonucleotide probes used for FISH

\begin{tabular}{|ccllll}
\hline $\begin{array}{c}\text { Phylogenetic } \\
\text { group of oral } \\
\text { treponemes }\end{array}$ & $\begin{array}{c}\text { Oligonucleotide } \\
\text { probe }\end{array}$ & Sequence $\left(\mathbf{5}^{\prime} \rightarrow \mathbf{3}^{\prime}\right)$ & Reference & $\begin{array}{c}\text { Cultivable } \\
\text { representative }\end{array}$ \\
\hline I & TRE I & ACGCAAGCTCATCCTCAAG & Choi et al. (1997) & T. vincentii \\
II & TRE II & GCTCCTTTCCTCATTTACCTTTAT & Moter et al. (1998) & T. denticola \\
IV & TRE IV & CGGTCACATTCGGTATTACCTACT & Moter et al. (1998) & T. maltophilum \\
- & DDK4 & ACAGTCTCGCTTCACTTTGTAG & Choi et al. (1997) & T.phagedenis \\
\hline
\end{tabular}


sections of plasic-embedded cultures. Control slides with fixed treponeme cultures were included in every hybridization experiment with tissue sections. Of all 10 biopsies, at least three sections were investigated in three different hybridization experiments. Pre-warmed hybridization solution $(20 \mu \mathrm{l})$ was mixed with approximately $5 \mathrm{pmol}$ of the appropriate oligonucleotide probe and carefully applied to the tissue sections. After incubation for $3.5 \mathrm{~h}$ in a dark humid chamber at $46{ }^{\circ} \mathrm{C}$, slides were washed with pre-warmed buffer $(20 \mathrm{mM}$ Tris/ $\mathrm{HCl}, \mathrm{pH} 7 \cdot 4,0 \cdot 01 \%$ SDS) for $15 \mathrm{~min}$ at $46^{\circ} \mathrm{C}$. The $\mathrm{NaCl}$ concentration was adjusted from 0.112 to $0.45 \mathrm{M}$, according to the formamide concentration in the hybridization solution. Slides were then rinsed with distilled water, air-dried in the dark and mounted with Citifluor AF 1 (Chemical laboratory of the University of Kent). Paraffin sections were dewaxed in xylene for $15 \mathrm{~min}$ and rehydrated in 96,70 and $50 \%(\mathrm{v} / \mathrm{v})$ ethanol ( 5 min each) prior to hybridization.

Epifluorescent microscopy and CLSM. A Zeiss Axioskop epifluorescence microscope was used to view the bacteria in sections processed for FISH. The microscope was equipped with a $50 \mathrm{~W}$ high pressure mercury lamp (HBO50, Osram) and $10 \times, 40 \times$ and $100 \times$ objectives (Zeiss). Narrow band Filter sets HQ-F41-007 and HQ-F41-001 (AHF) were used to analyse FITC and $\mathrm{Cy} 3$ signals, respectively. Photomicrographs were taken on Kodak Ektachrome HC 400 film. A Zeiss LSM 410 scanning confocal microscope equipped with an Ar-ion laser (488 $\mathrm{nm}$ ) and two HeNe lasers (543 and $633 \mathrm{~nm}$ ) was used to record optical sections. Image processing was performed with a standard software package delivered with the instrument (Zeiss LSM version 3.95). Reconstructed and processed images were reproduced on slide film (Kodak Professional, HC 100).

\section{RESULTS}

\section{Histology of DD lesions}

H\&E staining of the skin sections revealed signs of acute inflammation with a highly hyperplastic epidermis and pronounced rete-ridge formation. The corneal, granulosal and superficial spinosal cell layers were eroded and the tips of the dermal papillae were ulcerated (Fig. 1a). Erythrocytes, leukocytes and debris of destroyed keratinocytes were mixed with particulate material and micro-organisms, and covered the lesion as a crust.

\section{Embedding procedure and hybridization conditions}

Skin biopsies were embedded into the cold polymerizing resin Technovit 8100 . The entire procedure required $2 \mathrm{~d}$, but only $1 \mathrm{~h}$ of actual laboratory work. Biopsies up to $10 \times 5 \times 3 \mathrm{~mm}$ could be processed easily. Sectioning of soft and hard tissue was equally feasible with exactly defined thickness ranging from 1 to $30 \mu \mathrm{m}$. Conditions for conventional FISH protocols for touch preparations were easily adapted to tissue FISH. Stringent hybridization conditions were determined for each probe using sections of plastic-embedded or fixed treponeme cultures (data not shown). Optimal hybridization stringency was achieved by adding formamide to the hybridization buffer: $10 \%$ final concentration for TRE I and IV, 20\% for TRE II and DDK4. However, as no significant reduction in signal intensity for TRE I and IV was observed using $20 \%$ formamide, all hybridizations were performed at this concentration. Resin sections did not require any further treatment, such as etching or dehydration, before applying the hybridization solution. When silanized slides were used, there was no need for coverslips or sealing of the samples because the hybridization solution remained on the plastic sections without floating off the slide. Tissue sections could be stored for up to 6 months without any significant signal reduction. After hybridization, the slides could be examined within 1 week. The preparations were analysed equally well by epifluorescent microscopy and confocal laser scanning microscopy (CLSM). However, epifluorescence microscopy allowed a better orientation within the tissue, whereas CLSM allowed three-dimensional reconstruction (data not shown) and exact localization of the micro-organisms outside the cells.

\section{Direct visualization of bacteria by FISH}

To identify tissue-invasive treponemes possibly involved in the pathogenesis of disease, the spatial distribution of spirochaetes within the epidermis of DD ulcers was investigated using FISH on sections of tissue embedded in the cold polymerizing resin Technovit 8100 . Excellent morphological resolution provided exact histological orientation within the tissue. A high signal-to-noise ratio and the slight autofluorescent background allowed location of bacteria within the epidermis. From all 10 biopsies, three sections each were used in independent experiments. Hybridization with EUB 338 showed a variety of different bacterial morphotypes mixed with autofluorescent erythrocytes in the debris covering the ulcer. Simultaneous hybridization with probe DDK4 revealed large numbers of spirochaetes in this area. While most of the EUB 338-stained bacteria were visible in the debris on the surface of the ulcer, the majority of treponemes were located within the tissue (Fig. 1b). Focusing on the spinosal cell layers of the epidermis, DDK4-positive bacteria appeared to be in bundles around the cells and directed towards the dermis. No spiral-shaped and long stretched bacteria were visualized in this region using EUB 338 (Fig. 1c). CLSM confirmed that the treponemes were indeed located around the cells (Fig. 1d), whereas no bacteria were visible within cells.

Three biopsies were further analysed by using different combinations of specific oligonucleotide probes simultaneously, revealing a stratification of different treponemal phylotypes within the epidermis (Fig. 2). Group II treponemes ( $T$. denticola-related) were only detected in the very superficial layers (Fig. 2b), whereas TRE IV- (data not shown), TRE I- and DDK4-positive 

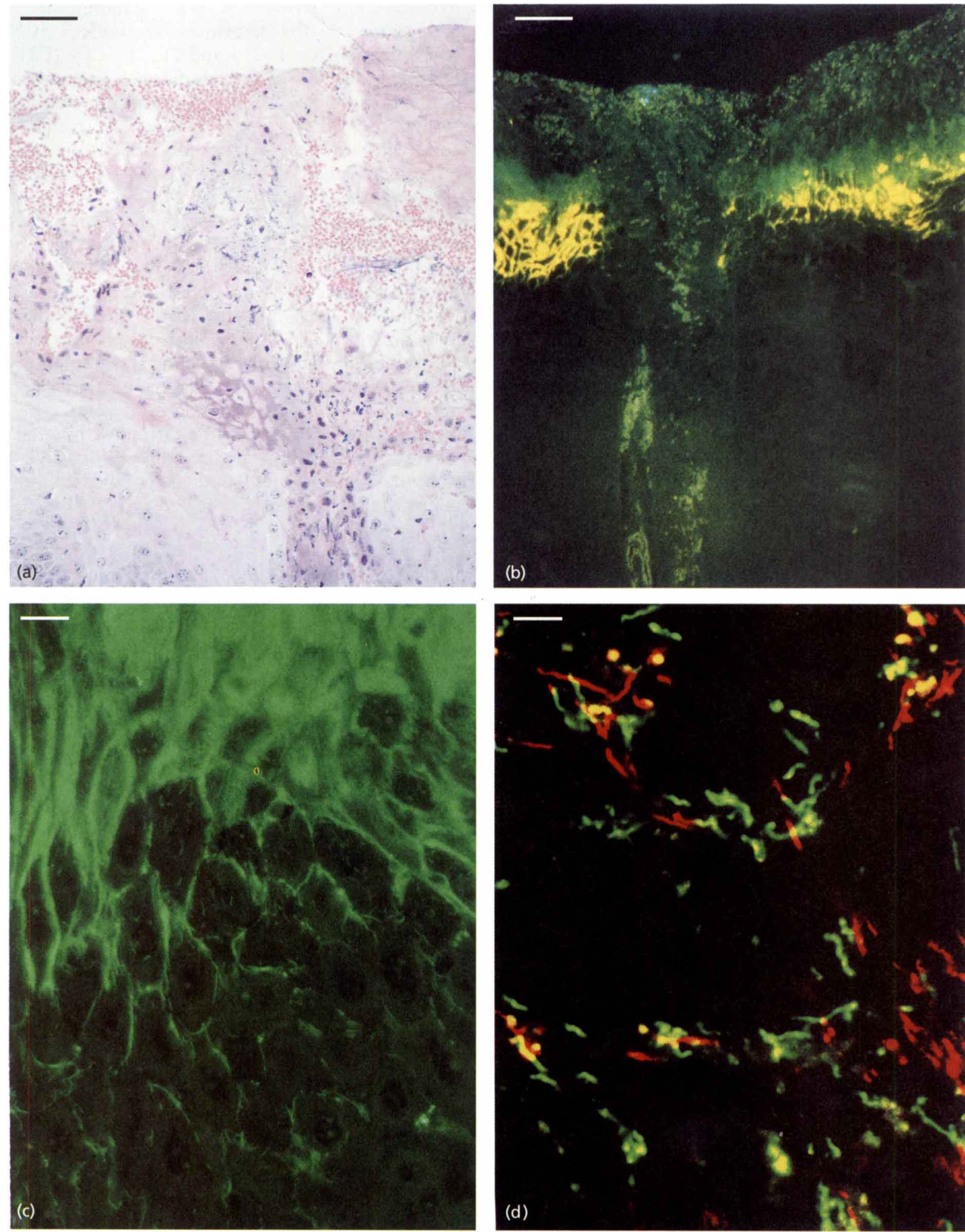

Fig. 1. For legend see facing page.

treponemes migrated deep into the stratum spinosum (Fig. 1e). Using EUB 338, an additional distinct morphotype of long stretched bacteria, not detectable with any of the other probes used here, was visualized deep in the epidermis next to the dermal papillae.
The same FISH protocol used on paraffin sections did not give satisfactory results. The bacteria appeared rather hazy and hard to distinguish in the high background of non-specifically stained material (data not shown). 

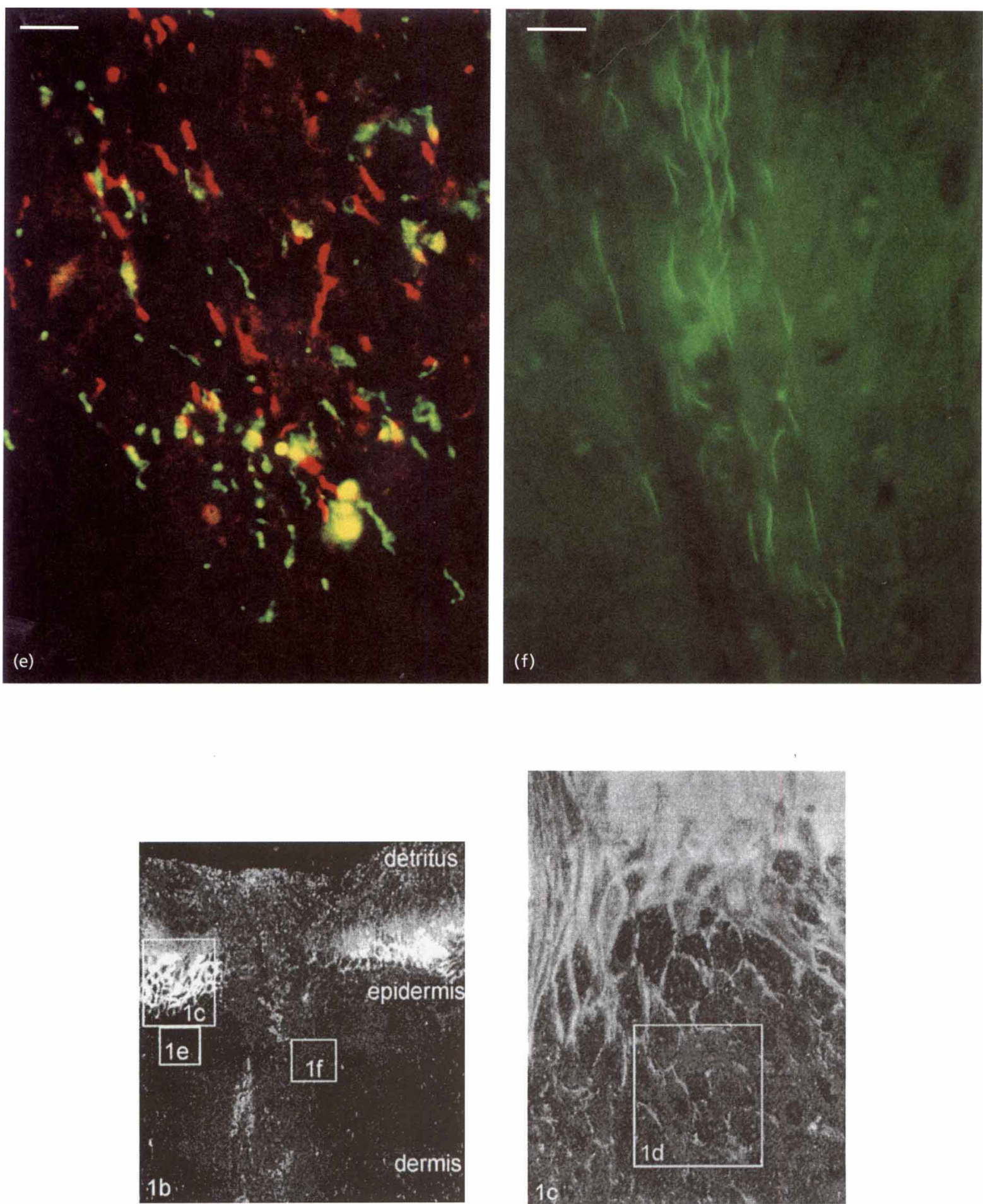

Fig. 1. Histopathology and FISH of tissue sections from DD lesions. (a) H\&E staining showing typical histology with necrotic superficial epidermal layers. Bar, $50 \mu \mathrm{m}$. (b) FISH of the same area using universal probe EUB $338_{\mathrm{FITC}}$ (green) and DDK $4_{C y 3}$ (yellow) exhibits stratification of fluorescence signals, localizing EUB 338-positive bacteria predominantly in the debris and DDK4-positive treponemes in the stratum corneum and stratum spinosum. Bar, $50 \mu \mathrm{m}$. (c) Using the FITC filter set, no rods or cocci were detected by EUB 338. In the upper part of the micrograph large numbers of micro-organisms are visible. Bar, $10 \mu \mathrm{m}$. (d, e) Deeper in the tissue single spirochaetes are visible between cells directed towards the dermis. CLSM of simultaneous hybridization with TRE $\mathrm{I}_{\mathrm{C}_{5}}$ (green) and DDK $4_{\mathrm{Cy} 3}$ (red) shows both phylotypes migrating around the cells deep (d) and even deeper (e) within the tissue (e). Bars, $5 \mu \mathrm{m}$. (f) EUB 338-stained bacteria migrating deepest into the tissue are visible close to a dermal papilla. Bar, $5 \mu \mathrm{m}$. The diagram below (e) and (f) shows the relationship between the various parts of the figure. 

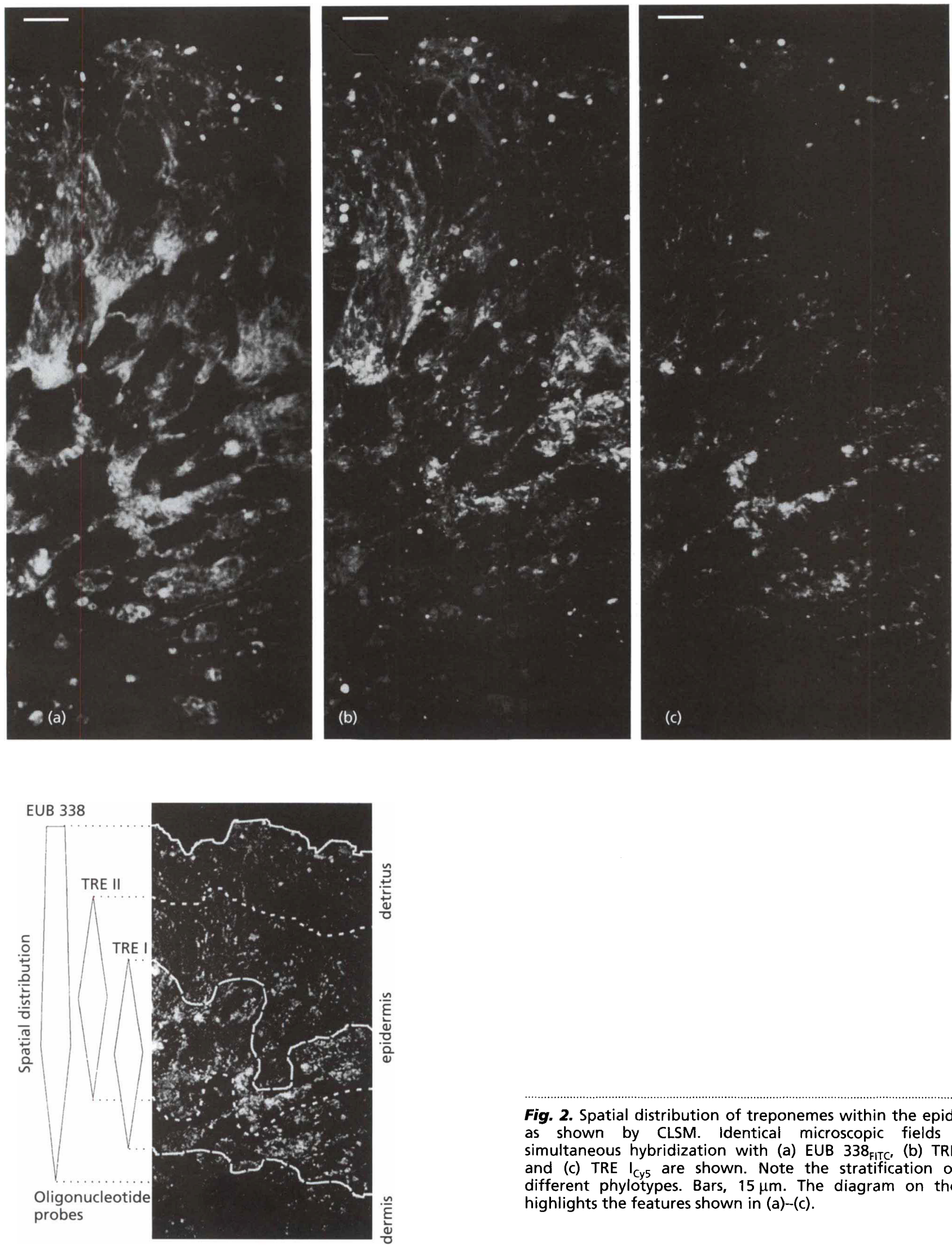

Fig. 2. Spatial distribution of treponemes within the epidermis as shown by CLSM. Identical microscopic fields after simultaneous hybridization with (a) EUB $338_{\mathrm{FTTC}}$, (b) TRE $\|_{\mathrm{CY} 3}$ and (c) TRE $I_{C_{5}}$ are shown. Note the stratification of the different phylotypes. Bars, $15 \mu \mathrm{m}$. The diagram on the left highlights the features shown in (a)--(c). 


\section{DISCUSSION}

FISH is a powerful technique for the investigation of mixed populations of micro-organisms in their natural environments. It has been used to visualize cultivable and as yet uncultured bacteria in activated sludge (Wagner et al., 1994a, b, 1995) and in clinical and pathological samples (McNicol \& Farquharson, 1997). It enables phylogenetic identification using $16 \mathrm{~S}$ rRNAdirected oligonucleotide probes in addition to providing information on size, morphology and numbers of bacteria. The method has been further improved by CLSM, allowing optical sectioning, three-dimensional reconstruction and therefore exact localization and observation of the spatial distribution of microorganisms (Amann et al., 1996; MacNaughton et al., 1996; Manz et al., 1995; Surmann et al., 1996; Wilson, 1989; Wright \& Schatten, 1991).

In the past, visualization of bacteria by FISH within biopsy sections was hampered by high levels of nonspecific background staining in paraffin-embedded tissue (Licht et al., 1996; Poulsen et al., 1994). Better results have been reported using cryostat sections; however, a low signal-to-noise ratio did not allow the exact histological localization and simultaneous detailed morphological description of the target organisms (Forsgren et al., 1994, 1996). Bacteria have been successfully detected in tissue sections by using radioactively labelled (Ward et al., 1996), digoxigenin-labelled or sulphonated probes with subsequent immunoenzymic detection, although all three methods require extensive prehybridization, blocking, washing and detection steps. Therefore, ISH has been considered a laborious, timeconsuming method, unsuitable for diagnostic investigations (Theil et al., 1996). Furthermore, additional pretreatment of the sections with Proteinase $\mathrm{K}$ is often necessary to allow binding of the oligonucleotide probes (Arnoldi et al., 1992; Karttunen et al., 1996; Yoshii et al., 1995). In some specimens only weak signals have been obtained even after proteinase digestion (Yoshii et al., 1995) and high concentrations of Proteinase K have resulted in tissue destruction (Karttunen et al., 1996). Since we were interested in elucidating the aetiology of mixed infections, such as DD or human periodontitis, the use of oligonucleotide probes labelled with different fluorescent dyes would allow simultaneous visualization of more than one bacterial species within inflamed tissue. Recent comparative 16S rRNA analysis has allowed determination of the phylogeny of mainly uncultured spirochaetes in both DD and human periodontitis (Choi et al., 1997, 1994; Rijpkema et al., 1997). Light microscopy showed that spirochaetes were the predominant morphotype in both diseases. However, as these diseases are mixed bacterial infections, the mere presence of a given species or morphotype does not prove its aetiological relevance.

Among the cultivable oral species, $T$. denticola, a member of the group II treponemes, is thought to play a mayor role in initiating and maintaining periodontitis. Extensive in vitro studies have been performed to analyse its virulence factors, suggesting the invasive potential of $T$. denticola (Arakawa \& Kuramitsu, 1994; Baehni et al., 1992; Ellen et al., 1994; Grenier et al., 1990; Rosen et al., 1994, 1995; Syed et al., 1993; Uitto et al., 1995). Closely related bacteria were detected in smears of DD lesions using $16 \mathrm{~S}$ rRNA analysis. In the study reported here, FISH gave positive signals with TRE II only in detritus and superficial layers of the stratum spinosum of DD ulcers, suggesting that $T$. denticola-related treponemes were not the key pathogens in the cases investigated. However, treponemes residing deep within the tissue stained positive with probes DDK 4, TRE I and IV, the latter two having been originally designed for detection of oral treponemes (Moter et al., 1998). The morphotype that migrated deepest into the epidermis only stained positive with EUB 338, but failed to react with any of the spirochaete probes used here. This might be due to the fact that the available probes do not enable detection of all spirochaetes, underlining the considerable diversity of this group. In addition, at present it cannot be excluded that these organisms may be fusobacteria, known to coaggregate with oral treponemes (Kolenbrander et al., 1995) and further FISH studies are required to address this question.

In conclusion, fluorescence in situ hybridization on sections of plastic-embedded tissue appears to be of potential value in elucidating the aetiopathogenesis of mixed bacterial infections and in allowing rapid diagnosis in infections in animals and man. In particular, FISH on tissue sections of DD-infected cows showed a spatial distribution of as yet uncultured treponemes within the epidermis. Since tissue invasion is considered a major virulence trait, some treponemes appear to have a role in the pathogenesis of this disease.

\section{ACKNOWLEDGEMENTS}

This study has been supported by a grant from the Bundesministerium für Bildung und Forschung (01KI9318) to U.B.G. The authors would like to thank K. Heuner and R. Schumann for carefully reading the manuscript.

\section{REFERENCES}

Amann, R. I., Binder, B. J., Olson, R. J., Chisholm, S. W., Devereux, R. \& Stahl, D. A. (1990). Combination of $16 \mathrm{~S}$ rRNA-targeted oligonucleotide probes with flow cytometry for analyzing mixed microbial populations. Appl Environ Microbiol 56, 1919-1925.

Amann, R., Springer, N., Ludwig, W., Görtz, H.-D. \& Schleifer, K. H. (1991). Identification in situ and phylogeny of uncultured bacterial endosymbionts. Nature 351, 161-164.

Amann, R., Snaidr, J., Wagner, M., Ludwig, W. \& Schleifer, K. H. (1996). In situ visualization of high genetic diversity in a natural microbial community. J Bacteriol 178, 3496-3500.

Arakawa, S. \& Kuramitsu, H. K. (1994). Cloning and sequence analysis of a chymotrypsin like protease from Treponema denticola. Infect Immun 62, 3424-3433.

Arnoldi, J., Schlüter, C., Duchrow, M., Hübner, L., Ernst, M., Teske, A., Flad, H.-D., Gerdes, J. \& Böttger, E. C. (1992). Speciesspecific assessment of Mycobacterium leprae in skin biopsies by 
in situ hybridization and polymerase chain reaction. Lab Investig 66, 618-623.

Baehni, P. C., Song, M., McCulloch, A. G. \& Ellen, R. P. (1992). Treponema denticola induces actin rearrangement and detachment of human gingival fibroblasts. Infect Immun 60, 3360-3368.

Blowey, R. W. \& Sharp, M. W. (1988). Digital dermatitis in dairy cattle. Vet Rec 122, 505-508.

Blowey, R. W., Sharp, M. W. \& Done, S. H. (1992). Digital dermatitis. Vet Rec 131, 39.

Blowey, R. W., Done, S. H. \& Cooley, W. (1994). Observation on the pathogenesis of digital dermatitis in cattle. Vet Rec 135, 115-117.

Cheli, R. \& Mortellaro, C. (1974). La dermatite digitale del bovino. In Proceedings of the 8th International Conference on Diseases of Cattle, pp. 208-213.

Choi, B.-K., Paster, B. J., Dewhirst, F. E. \& Göbel, U. B. (1994), Diversity of cultivable and uncultivable oral spirochetes from a patient with severe destructive periodontitis. Infect Immun 62, 1889-1895.

Choi, B.-K., Nattermann, H., Grund, S., Haider, W. \& Göbel, U. B. (1997). Spirochetes from digital dermatitis lesions in cattle are closely related to treponemes associated with human periodontitis. Int J Syst Bacteriol 47, 175-181.

DeLong, E. F., Wickham, G. S. \& Pace, N. R. (1989). Phylogenetic strains: ribosomal RNA-based probes for the identification of single microbial cells. Science 243, 1360-1363.

Done, S. H., Blowey, R. W. \& Cooley, W. (1993). The pathology of digital dermatitis in cattle in the UK. In Proceedings of the American Association of Veterinary Laboratory Diagnosticians Meeting, Las Vegas, Nevada, p. 69.

Elias, E. A. \& Bosma, R. (1987). Silver staining for micro-organisms in tissue sections of paraffin and plastic-embedded material. Cell Mol Biol 33, 711-732.

Ellen, R. P., Dawson, J. R. \& Yang, P. F. (1994). Treponema denticola as a model for polar adhesion and cytopathogenicity of spirochetes. Trends Microbiol 2, 114-119.

Forsgren, J., Samuelson, A., Ahlin, A., Jonasson, J., RynnelDagöö, B. \& Lindberg, A. (1994). Haemophilus influenzae resides and multiplies intracellularly in human adenoid tissue as demonstrated by in situ hybridization and bacterial viability assay. Infect Immun 62, 673-679.

Forsgren, J., Samuelson, A., Borrelli, S., Christensson, B., Jonasson, J. \& Lindberg, A. (1996). Persistance of nontypeable Haemophilus influenzae in adenoid macrophages: a putative colonization mechanism. Acta Oto-laryngol 116, 766-773.

Grenier, D., Uitto, V.-J. \& McBride, B. C. (1990). Cellular location of a Treponema denticola chymotrypsin like protease and importance of the protease in migration through the basement membrane. Infect Immun 58, 347-351.

Karttunen, T. J., Genta, R. M., Yoffe, B., Hachem, C. Y., Graham, D. Y. \& El-Zaatari, F. A. (1996). Detection of Helicobacter pylori in paraffin embedded gastric biopsy specimens by in situ hybridization. Anat Pathol 106, 305-311.

Kolenbrander, P. E., Parrish, K. D., Andersen, R. N. \& Greenberg, E. P. (1995). Intergeneric coaggregation of oral Treponema spp. with Fusobacterium spp. and intrageneric coaggregation among Fusobacterium spp. Infect Immun 63, 4584-4588.

Licht, T. R., Krogfelt, K. A., Cohen, P. S., Poulsen, L. K., Urbance, J. \& Molin, S. (1996). Role of lipopolysaccharide in colonization of the mouse intestine by Salmonella typhimurium studied by in situ hybridization. Infect Immun 64, 3811-3817.
MacNaughton, S. J., Booth, T., Embley, T. M. \& O'Donnell, A. G. (1996). Physical stabilization and confocal microscopy of bacteria on roots using $16 \mathrm{~S}$ rRNA targeted, fluorescent-labeled oligonucleotide probes. J Microbiol Methods 26, 279-285.

McNicol, A. M. \& Farquharson, M. A. (1997). In situ hybridization and its diagnostic applications in pathology. I Pathol 182, 250-261.

Manz, W., Amann, R., Szewzyk, R., Szewzyk, U., Stenström, T.-A., Hutzler, P. \& Schleifer, K.-H. (1995). In situ identification of Legionellaceae using $16 \mathrm{~S}$ rRNA-targeted oligonucleotide probes and confocal laser scanning microscopy. Microbiology 141, 29-39.

Moter, A., Hoenig, C., Choi, B.-K., Riep, B. \& Göbel, U. B. (1998). Molecular epidemiology of oral treponemes in periodontal disease. J Clin Microbiol 36, 1399-1403.

Poulsen, L. K., Lan, F., Kristensen, C. S., Hobolth, P., Molin, S. \& Krogfelt, K. A. (1994). Spatial distribution of Escherichia coli in the mouse large intestine inferred from rRNA in situ hybridization. Infect Immun 62, 5191-5194.

Read, D. H., Walker, R. L., Castro, A. E., Sundber, J.P. \& Thurmond, M. C. (1992). An invasive spirochaete associated with interdigital papillomatosis of dairy cattle. Vet Rec 130, 59-60.

Rijpkema, S. G. T., David, G. P., Hughes, S. L. \& Woodward, M. J. (1997). Partial identification of spirochaetes from two dairy cows with digital dermatitis by polymerase chain reaction analysis of the $16 \mathrm{~S}$ ribosomal RNA gene. Vet Rec 140, 257-259.

Rosen, G., Naor, R., Kutner, S. \& Sela, M. N. (1994). Characterization of fibrinolytic activities of Treponema denticola. Infect Immun 62, 1749-1754.

Rosen, G., Naor, R., Rahamim, E., Yishai, R. \& Sela, M. N. (1995). Proteases of Treponema denticola outer sheath and extracellular vesicles. Infect Immun 63, 3973-3979.

Surmann, S. B., Walker, J. T., Goddard, D. T., Morton, L. H. G., Keevil, C. W., Weaver, W., Skinner, A., Hanson, K., Caldwell, D. \& Kurtz, J. (1996). Comparison of microscope techniques for the examination of biofilms. J Microbiol Methods 25, 57-70.

Syed, S. A., Mäkinen, K. K., Mäkinen, P.-J., Chen, C.-Y. \& Muhammad, Z. (1993). Proteolytic and oxireductase activity of Treponema denticola ATCC 35405 grown in an aerobic and anaerobic gaseous environment. Res Microbiol 144, 317-326.

Theil, D., Hoop, R., Herring, A. J. \& Pospischil, A. (1996). Detection of chlamydia in formalin-fixed and paraffin-embedded avian tissue by in situ hybridization. A comparison between in situ hybridization and peroxidase-antiperoxidase labeling. J Vet Med B 43, 356-370.

Uitto, V.-J., Pan, Y.-M., Keung Leung, W., Larjava, H., Ellen, R. P., Finlay, B. B. \& McBride, B. C. (1995). Cytopathic effects of Treponema denticola chymotrypsin-like proteinase on migrating and stratified epithelial cells. Infect Immun 63, 3401-3410.

Wagner, M., Amann, R., Kämpfer, P., Aßmus, B., Hartmann, A., Hutzler, P., Springer, N. \& Schleifer, K.-H. (1994a). Identification and in situ detection of Gram-negative filamentous bacteria in activated sludge. Syst Appl Microbiol 17, 405-417.

Wagner, M., Aßmus, B., Hartmann, A., Hutzler, P. \& Amann, R. (1994b). In situ analysis of microbial consortia in activated sludge using fluorescently labeled rRNA targeted oligonucleotide probes and scanning confocal laser microscopy. J Microsc (Oxf) 176, 181-187.

Wagner, M., Rath, G., Amann, R., Koops, H.-P. \& Schleifer, K.-H. (1995). In situ identification of ammonia-oxidizing bacteria. Syst Appl Microbiol 18, 251-264. 
Ward, J. M., Benveniste, R. E., Fox, C. H., Battles, J. K., Gonda, M. A. \& Tully, J. G. (1996). Autoimmunity in chronic active Helicobacter hepatitis of mice. Am J Pathol 148, 509-517.

Weaver, A. D. \& Court, C. M. (1993). Current concepts of digital dermatitis and papillomatosis in cattle. In 2. Internationaler Kongreß für Orthopädie bei Huf-und Klauentieren, pp. 165-170.

Wilson, T. (1989). Confocal light microscopy. Ann N Y Acad Sci 438, 416-426.

Wright, S. J. \& Schatten, G. (1991). Confocal fluorescence microscopy and three dimensional reconstruction. J Electron Microsc Tech 18, 2-10.
Wyss, C., Choi, B.-K., Schüpbach, P., Guggenheim, B. \& Göbel, U. B. (1996). Treponema maltophilum sp. nov., a small oral spirochete isolated from human periodontal lesions. Int J Syst Bacteriol 46, 745-752.

Yoshii, A., Koji, T., Ohsawa, N. \& Nakane, P. K. (1995). In situ localization of ribosomal RNAs is a reliable reference for hybridizable RNA in tissue sections. J Histochem Cytochem 43, 321-327.

Received 21 January 1998; revised 7 May 1998; accepted 19 May 1998. 